\title{
Influence of exogenous and endogenous estrogen on thermoregulatory responses to mild heat and the interaction with light and dark phases
}

\author{
Shuri Marui ${ }^{1}$, Yuta Masuda ${ }^{1,2}$, Issei Kato ${ }^{1,2}$ and Kei Nagashima ${ }^{1 *}$ (i)
}

\begin{abstract}
The present study aimed to determine the influence of estradiol $\left(E_{2}\right)$ and the interaction with circadian phases on thermoregulatory responses to mild heat in female rats. Heat loss and production during 3-h exposure to the environment at an ambient temperature of $28-34^{\circ} \mathrm{C}$ were assessed by measuring abdominal temperature $\left(T_{\text {abd }}\right)$, tail skin temperature, and oxygen consumption in ovariectomized rats with and without $E_{2}$ replacement $\left(O V X+E_{2}\right.$ and OVX, respectively) and in control rats in the proestrus (P) and diestrus (D) phases. In the light phase, $T_{\text {abd }}$ remained unchanged in all groups. $T_{\text {abd }}$ increased in the dark phase, but was lower in the $\mathrm{OVX}+\mathrm{E}_{2}$ and $\mathrm{P}$ groups than in the OVX and D groups. Oxygen consumption decreased at $34^{\circ} \mathrm{C}$, but to a lesser extent in the $\mathrm{OVX}+\mathrm{E}_{2}$ group than in the OVX group. These results suggest that $\mathrm{E}_{2}$ activates thermoregulation in mild heat in the dark phase.
\end{abstract}

Keywords: Female hormones, Circadian rhythm, Autonomic thermoregulation, Core temperature, Hot environment

\section{Background}

Several studies have reported that estradiol $\left(\mathrm{E}_{2}\right)$ activates thermoregulatory mechanisms during exposure to heat in female rats [1-5]. Baker et al. [1] demonstrated that, in the extreme heat of $38{ }^{\circ} \mathrm{C}$, the increase in body temperature was greater in ovariectomized (OVX) rats than in OVX rats with $\mathrm{E}_{2}$ replacement $\left(\mathrm{OVX}+\mathrm{E}_{2}\right)$. They suggested that reduced evaporative heat loss in OVX rats is involved in the mechanism. However, Dacks and Rance [2] reported that the increase in body temperature was greater in OVX rats than in OVX $+\mathrm{E}_{2}$ even at an ambient temperature $\left(T_{\mathrm{a}}\right)$ of $32.5{ }^{\circ} \mathrm{C}$, a temperature at which evaporative heat loss is less involved in thermoregulation [6]. They also reported that dry heat loss from the tail

\footnotetext{
*Correspondence: k-nagashima@waseda.jp

${ }^{1}$ Body Temperature and Fluid Laboratory, Faculty of Human Sciences, Waseda University, Mikajima 2-579-15, Tokorozawa, Saitama 359-1192, Japan

Full list of author information is available at the end of the article
}

was greater in OVX rats than in $\mathrm{OVX}+\mathrm{E}_{2}$ rats. Hosono et al. [3] reported that, at $T_{\mathrm{a}}$ of $32-36{ }^{\circ} \mathrm{C}$, heat-escape behavior did not differ between OVX and OVX $+\mathrm{E}_{2}$ rats. These results suggest that $E_{2}$ activates neither the heat loss response of the tail nor thermoregulatory behavior in mild heat. Thus, it remains unclear how $E_{2}$ attenuates the increase in body temperature in mild heat. Previous studies have reported that acute and chronic heat exposure suppress metabolism with attenuation of thyroid function [7, 8] and/or decreased spontaneous activity [9]. The results suggest that the attenuation of metabolism is part of the thermoregulatory response to heat, although it is unclear whether $E_{2}$ is involved in the underlying mechanism.

Endothermic animals exhibit circadian changes in body temperature, metabolism, and spontaneous activity. In addition, some studies have demonstrated the involvement of $E_{2}$ in these changes. For example, body temperature is lower in OVX rats than in OVX $+\mathrm{E}_{2}$ rats in the

(c) The Author(s) 2020. This article is licensed under a Creative Commons Attribution 4.0 International License, which permits use, sharing, adaptation, distribution and reproduction in any medium or format, as long as you give appropriate credit to the original author(s) and the source, provide a link to the Creative Commons licence, and indicate if changes were made. The images or other third party material in this article are included in the article's Creative Commons licence, unless indicated otherwise in a credit line to the material. If material is not included in the article's Creative Commons licence and your intended use is not permitted by statutory regulation or exceeds the permitted use, you will need to obtain permission directly from the copyright holder. To view a copy of this licence, visit http://creativeco mmons.org/licenses/by/4.0/. 
middle of the dark phase [10]. Further, Williams et al. [11] reported that $E_{2}$ reduces the tail skin temperature in the dark phase, indicating the heat loss response of the tail. These results suggest that, when evaluating the influence of $E_{2}$ on thermoregulatory responses to heat, we need to consider the concurrent influence of circadian changes. However, no studies have yet evaluated this influence. Therefore, the aim of this study was to identify the mechanism by which $E_{2}$ activates thermoregulatory responses during exposure to mild heat in female rats, and to determine whether the influence of $E_{2}$ differs between circadian cycles. Therefore, we exposed OVX rats with and without $\mathrm{E}_{2}$ replacement to the environment at $28-34{ }^{\circ} \mathrm{C}$ and compared the body temperature and heat loss and metabolic responses between the light and dark phases. Moreover, to know if physiological change in plasma $E_{2}$, normally observed within the estrus cycle, also affect the responses to the mild heat, the same heat exposure was conducted in the control female rats with the proestrus and diestrus phases, in which plasma $E_{2}$ is higher and lower, respectively.

\section{Methods}

\section{Animals}

Adult virgin female Wistar rats $(n=48$; body weight, $249 \pm 25 \mathrm{~g}$ [mean \pm standard deviation]); age, 9-11 weeks; Takasugi Experimental Animals Supply, Saitama, Japan) were used in the present study. They were housed individually in plastic cages $(45 \mathrm{~cm} \times 25 \mathrm{~cm} \times 20 \mathrm{~cm})$ at a $T_{\mathrm{a}}$ of $25{ }^{\circ} \mathrm{C}$ under a $12 / 12 \mathrm{~h}$ light/dark cycle (lights on at 07:00). Food and water were freely available. Animal experiments and care were conducted in accordance with the institutional guidelines, which follow the Fundamental Guidelines for Proper Conduct of Animal Experiments and Related Activities in Academic Research Institutions under the jurisdiction of the Ministry of Education, Culture, Sports, Science, and Technology (Notice No. 71, 2006; Tokyo, Japan). The Institutional Animal Care and Use Committee of Waseda University (Tokyo, Japan) approved all experimental procedures applied in the present study (Approval No. A071).

\section{Surgery}

Rats were divided to two groups that were used in two different experiments (i.e., Experiments 1 and 2; $n=28$ and 20, respectively). Under inhalation anesthesia with $2 \%$ isoflurane (Abbott Japan, Tokyo, Japan) in air, a radiotransmitter device with two wire-type thermistors was placed in the abdominal cavity of each rat to measure abdominal temperature $\left(T_{\mathrm{abd}}\right)$, tail temperature $\left(T_{\text {tail }}\right)$, and spontaneous activity $\left(3.5 \mathrm{~cm}^{3}, 7.5 \mathrm{~g}\right.$; F40-TT transmitter; Data Sciences International, New Brighton, MN, USA) as previously described [12]. Briefly, having been passed through the muscle layer and subcutaneous tissue of the abdomen, the tip of one wire was placed under the skin of the lateral tail, $2 \mathrm{~cm}$ beyond the tail base. The other wire was fixed in the abdominal cavity. Spontaneous activity was estimated by the relative change in signal strength from the transmitter.

In Experiment 1, the rats were bilaterally ovariectomized with a retroperitoneal approach. A silicone tube (inner diameter, $1.57 \mathrm{~mm}$; outer diameter, $3.18 \mathrm{~mm}$; length, $30 \mathrm{~mm}$; Kaneka, Osaka, Japan) was placed in the subcutaneous tissue of the right side of the back, which was filled with $E_{2}$ powder (50-60 mg; Sigma-Aldrich, St. Louis, MO, USA; OVX $+\mathrm{E}_{2}, n=14$ ) or not filled with $\mathrm{E}_{2}$ powder $(\mathrm{OVX}, n=14) . \mathrm{E}_{2}$ is permeable to silicone and the placement provided a constant level of plasma $E_{2}$ for $>14$ days in OVX rats $[13,14]$. The rats recovered from the surgery after $\geq 14$ days. Penicillin G (1000 U; Meiji Pharmaceutical, Tokyo, Japan) was subcutaneously injected to prevent postsurgical infection.

In Experiment 2, a sham operation of the bilateral ovariectomy was performed. During the recovery period, vaginal smears from the rats were obtained every morning for $\geq 10$ days, and the estrus cycle was determined [15]. Rats exhibiting a regular estrus cycle of $4-5$ days were used for further experiments.

\section{Exposure to the environment at $28^{\circ} \mathrm{C}, 31^{\circ} \mathrm{C}$, and $34{ }^{\circ} \mathrm{C}$}

$T_{\text {abd }}, T_{\text {tail }}$, and spontaneous activity were recorded every $60 \mathrm{~s}$ with a data collection system (Dataquest ART; Data Sciences International). We verified that each rat showed clear circadian changes of these parameters. Then, each rat was moved to a Plexiglas box $(35 \mathrm{~cm} \times 20 \mathrm{~cm} \times 20 \mathrm{~cm})$ in a climatic chamber (Program Incubator IN604; Yamato Scientific, Tokyo, Japan), where oxygen consumption $\left(\dot{\mathrm{VO}}_{2}\right)$ was determined by indirect calorimetry. The box was attached to an airflow system with a flow rate of $2.01 \mathrm{~min}^{-1}$. The difference in oxygen tension between room air and the air that passed through the chamber was determined every $60 \mathrm{~s}$ with an electrochemical oxygen analyzer (model LC-700E; Toray, Tokyo, Japan). $\dot{\mathrm{VO}}_{2}$ was calculated as the product of the difference in oxygen tension and the airflow rate. The value was divided by 0.75 power of the body weight (i.e., Brody-Kleiber formula [16]) and corrected to the standard temperature and pressure dry condition. The chamber was maintained at $25.0 \pm 0.2{ }^{\circ} \mathrm{C}$ and the $T_{\mathrm{a}}$ was continuously recorded. For 3 days, the rats were housed in this condition, and the data on the last day were used as the control. In Experiment 1 , at 9:30 or 21:30 on the 4th day (exposure day), the rats were exposed to the environment at $28{ }^{\circ} \mathrm{C}, 31^{\circ} \mathrm{C}$, and $34^{\circ} \mathrm{C}$ for $1 \mathrm{~h}$ in sequence. The period in each phase was selected because $T_{\text {abd }}, T_{\text {tail }}$, and spontaneous activity are less influenced by the circadian fluctuations based on 
our preliminary finding. In Experiment 2, the day of the exposure was selected in the proestrus phase (P group, $n=10$ ) or the diestrus phase (D group, $n=10$ ). In both experiments, food and water were removed $2 \mathrm{~h}$ before heat exposure. Body weight was measured before and after exposure.

\section{Blood analysis}

After completion of the final heat exposure period, the rats were euthanized with an intraperitoneal injection of overdose pentobarbital sodium $\left(100 \mathrm{mg} \mathrm{kg}^{-1}\right.$ body weight: Kyoritsu Seiyaku, Tokyo, Japan). A $2 \mathrm{ml}$ blood sample was obtained from the right ventricle and centrifuged at $4{ }^{\circ} \mathrm{C}$, and the plasma was stored at $-80^{\circ} \mathrm{C}$ until use. The estradiol level in the plasma was determined using an enzyme-linked immunosorbent assay kit (Estradiol EIA Kit; Cayman Chemical, Ann Arbor, MI, USA). The detection limit of estradiol was $20 \mathrm{pg} \mathrm{ml}^{-1}$. The coefficient of variation of the measurement was $<13 \%$.

\section{Calculation and statistics}

The sample size was determined using $G^{*}$ Power 3.1.9.2 (Heinrich-Heine-University of Düsseldorf, Düsseldorf, Germany) [17]. To evaluate the parameters during heat exposure, we used an effect size of 0.4 , an $\alpha$ error probability of 0.05 , and a power $(1-\beta)$ of 0.8 . We estimated that the required sample size was at least five rats in each group.

The values for $T_{\mathrm{abd}}, T_{\text {tail }}$, spontaneous activity, and $\dot{\mathrm{VO}}_{2}$ during heat exposure were averaged every $30 \mathrm{~min}$. $\dot{\mathrm{V}} \mathrm{O}_{2}$ was corrected by body weight, which was averaged by the initial and final body weight. Thermal conductance from the body core to the environment (thermal conductance of the whole body) was calculated as $\dot{\mathrm{VO}}_{2} /\left(T_{\mathrm{abd}}-T_{\mathrm{a}}\right)$ $[18,19]$. The heat loss index of the tail was estimated as $\left(T_{\text {tail }}-T_{\mathrm{a}}\right) /\left(T_{\text {abd }}-T_{\mathrm{a}}\right)[20]$.

A two-way ANOVA or two-way ANOVA with repeated measurement (group $\times$ time) was performed to compare the values of the heat exposure day among the groups. When a significant difference was observed, post hoc Bonferroni tests were conducted. The null hypothesis was rejected at $P<0.05$. IBM SPSS Statistics for Windows (version 25.0.; IBM Corp., Armonk, NY, USA) was used for statistical analysis. All values are presented as means \pm standard error.

\section{Results}

\section{Body weight and plasma $\mathrm{E}_{\mathbf{2}}$ level}

Table 1 presents the initial and final body weight and plasma $\mathrm{E}_{2}$ level. In Experiment 1, there was a significant effect of time $\left[P<0.001, F_{(1,24)}=19.22\right]$ in body weight. In addition, a significant interaction between time and group was observed $\left[P<0.001, F_{(3,24)}=8.76\right]$. The final body weight was greater than the initial body weight in both phases in the OVX group $(P<0.001)$. Because of difference in recovery period from the surgery and adjustment of the estrus phase, the initial body weight on the exposure day varied in each group.

A significant effect of group $\left[P<0.001, F_{(3,20)}=14.35\right]$ was observed in plasma $\mathrm{E}_{2}$. In Experiment 1, the plasma $\mathrm{E}_{2}$ level was lower in the OVX group than the OVX $+\mathrm{E}_{2}$ group in both phases. In Experiment 2, the plasma $\mathrm{E}_{2}$ level was lower in the $\mathrm{D}$ group than the $\mathrm{P}$ group in the two phases. There were no differences between the OVX and $\mathrm{D}$ groups and the $\mathrm{OVX}+\mathrm{E}_{2}$ and $\mathrm{P}$ groups in each phase.

$T_{\text {abd }}, T_{\text {tail }}$ spontaneous activity, and $\dot{\mathrm{VO}}_{2}$ on the control day Figure 1 illustrates the circadian changes of $T_{\mathrm{abd}}$ and $T_{\text {tail }}$ before the 4-day protocol (i.e., those in home cages) in Experiments 1 and 2, shown in 30-min bins. In Experiment 1, there were significant interaction between time and group in $T_{\text {abd }}\left[P<0.001, F_{(47}\right.$, $\left.{ }_{564)}=2.8\right] . T_{\text {abd }}$ was lower in the OVX group than the OVX $+\mathrm{E}_{2}$ group at 9:00-9:30 and 0:00-1:30 $(P<0.05)$. There were significant interaction between time and

Table 1 Body weight and plasma $E_{2}$ level in Experiments 1 and 2

\begin{tabular}{|c|c|c|c|c|c|c|c|}
\hline & \multirow[t]{2}{*}{ Group } & \multicolumn{2}{|c|}{ Initial body weight, g } & \multicolumn{2}{|c|}{ Final body weight, g } & \multicolumn{2}{|c|}{ Plasma $E_{2}$ level, $\mathrm{pg} \mathrm{ml}^{-1}$} \\
\hline & & Light phase & Dark phase & Light phase & Dark phase & Light phase & Dark phase \\
\hline \multirow[t]{2}{*}{ Experiment 1} & OVX & $240 \pm 20$ & $254 \pm 23$ & $262 \pm 17^{\ddagger}$ & $273 \pm 21^{\ddagger}$ & $47 \pm 6$ & $53 \pm 4$ \\
\hline & $O V X+E_{2}$ & $228 \pm 9$ & $252 \pm 32$ & $244 \pm 13$ & $258 \pm 21$ & $142 \pm 25^{*}$ & $159 \pm 31^{*}$ \\
\hline \multirow[t]{2}{*}{ Experiment 2} & $D$ & $234 \pm 40$ & $224 \pm 7$ & $242 \pm 26$ & $240 \pm 6$ & $47 \pm 6$ & $43 \pm 12$ \\
\hline & $P$ & $250 \pm 24$ & $256 \pm 26$ & $254 \pm 10$ & $261 \pm 16$ & $125 \pm 29^{\dagger}$ & $119 \pm 6^{\dagger}$ \\
\hline
\end{tabular}

Data are presented as means \pm standard error

OVX, ovariectomized; $E_{2}$, estradiol; $D$, control rats in the diestrus phase; $P$, control rats in the proestrus phase

* Significant difference between the OVX and OVX $+\mathrm{E}_{2}$ groups $(P<0.05)$

+ Significant difference between the $D$ and $P$ groups $(P<0.05)$

₹ Significant difference from the initial body weight $(P<0.05)$ 

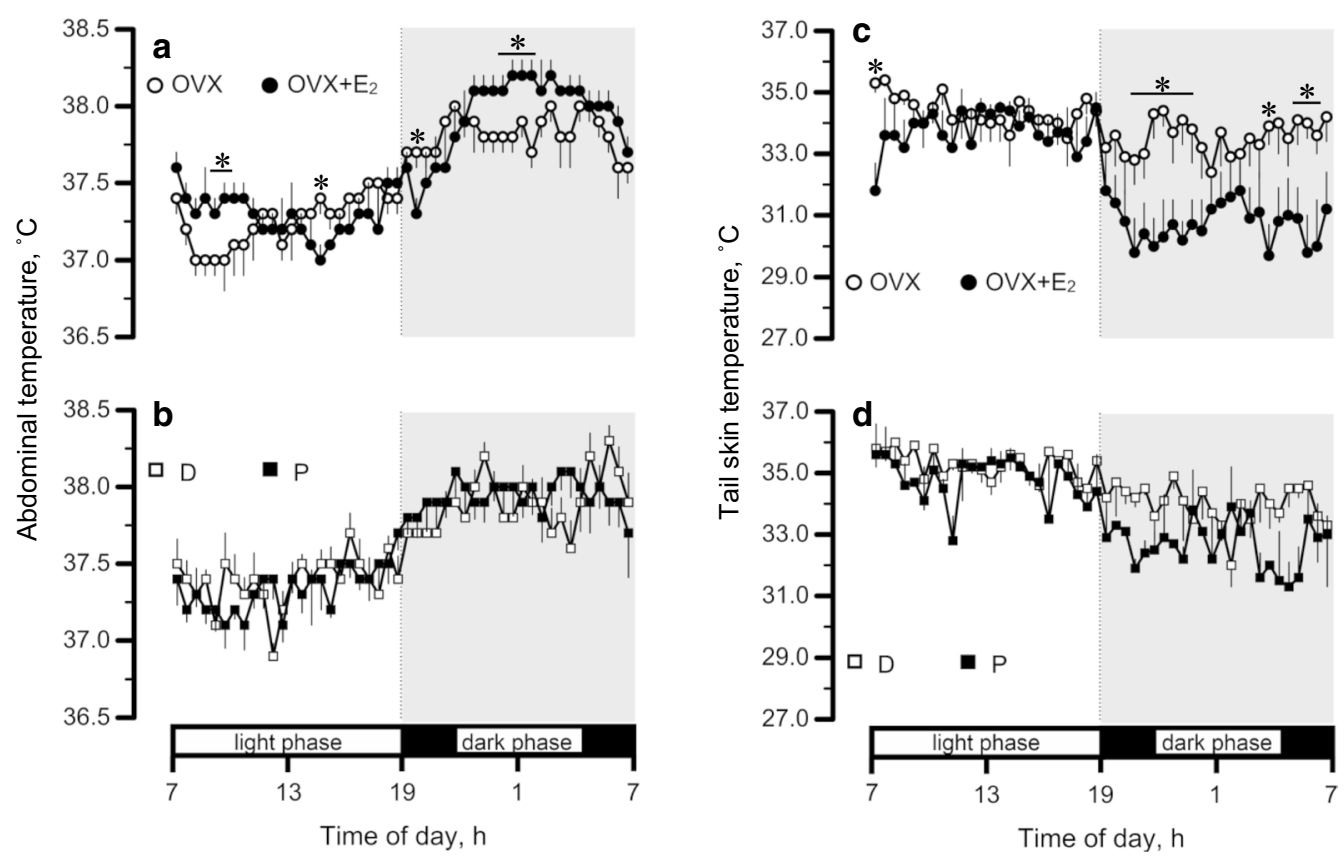

Fig. 1 Circadian changes of abdominal temperature $\left(T_{\text {abd }}\right)$ and tail temperature $\left(T_{\text {tail }}\right)$ in the ovariectomized $(O V X)$ and OVX + estradiol $\left(E_{2}\right)$ groups (open and closed circles, respectively), and in the $\mathrm{D}$ and $\mathrm{P}$ groups (open and closed squares, respectively). The data were obtained while rats were housed in the home cages. Data are presented as means \pm standard error (a and $\mathbf{c}, n=7$ in each group; $\mathbf{b}$ and $\mathbf{d}, n=5$ in each group). ${ }^{*} \operatorname{Significant}$ difference between the OVX and OVX $+E_{2}$ groups $(P<0.05)$. $D$, control rats in the diestrus phase; $P$, control rats in the proestrus phase

group in $T_{\text {tail }}\left[P<0.001, F_{(47,564)}=3.2\right] . T_{\text {tail }}$ was higher in the OVX group than the OVX $+\mathrm{E}_{2}$ group at 20:3023:30 and 5:00-6:00 $(P<0.05)$.

Table 2 summarizes the circadian changes of $T_{\mathrm{abd}}$, $T_{\text {tail }}$, spontaneous activity, and $\dot{\mathrm{V}} \mathrm{O}_{2}$ on the control day by calculating (i) the averages of the whole period and the light and dark phases, and (ii) the circadian amplitude (i.e., the difference between the maximum and minimum values). In Experiment 1, there were significant effects of phase $\left[P=0.003, F_{(1,12)}=13.63\right]$ and group $\left[P=0.032, F_{(1,12)}=5.89\right]$ with a significant interaction between the two factors $\left[P=0.039, F_{(1}\right.$, $\left.{ }_{12)}=5.34\right]$ in $T_{\text {tail }} \cdot T_{\text {tail }}$ was higher in the OVX group than the $\mathrm{OVX}+\mathrm{E}_{2}$ group in the dark phase $(P=0.011)$. The amplitude was smaller in the OVX group than the $\mathrm{OVX}+\mathrm{E}_{2}$ group $(P=0.006)$. In Experiment 2 , there were significant effects of phase $\left[P<0.001, F_{(1}\right.$, $\left.{ }_{8)}=62.51\right]$ and group $\left[P=0.008, F_{(1,8)}=12.36\right]$ with a significant interaction between these two factors $\left[P=0.04, F_{(1,8)}=6.03\right]$ in $T_{\text {tail }}$. In the dark phase, $T_{\text {tail }}$ was higher in the $\mathrm{D}$ group than the $\mathrm{P}$ group $(P=0.002)$. The amplitude was lower in the $\mathrm{D}$ group than the $\mathrm{P}$ group $(P=0.029) . T_{\text {abd }}$, spontaneous activity, and $\dot{\mathrm{V}} \mathrm{O}_{2}$ were higher in the dark phase than the light phase in all groups. In the $\mathrm{OVX}+\mathrm{E}_{2}$ and $\mathrm{P}$ groups, $T_{\text {tail }}$ was lower in the dark phase than the light phase.
$T_{\text {abd }}$ at $T_{\mathrm{a}}$ of $28^{\circ} \mathrm{C}, 31^{\circ} \mathrm{C}$, and $34^{\circ} \mathrm{C}$ in Experiments 1 and 2 Figure 2 shows $T_{\text {abd }}$ in Experiments 1 and 2. The difference in $T_{\text {abd }}$ between the same period on the exposure and control days $\left(T_{\mathrm{abd}}, \mathrm{H}-\mathrm{C}\right)$ is summarized as the $1 \mathrm{~h}$ average of each ambient condition (Fig. $2 \mathrm{a}^{\prime}-\mathrm{d}$ ). In Experiment 1 , there were significant effects of time $[P=0.003$, $\left.F_{(2,44)}=6.77\right]$ and group $\left[P=0.012, F_{(3,22)}=4.63\right]$ with a significant interaction between the two factors $\left[P=0.002, F_{(6,44)}=4.23\right]$. In the light phase, there were no differences in $T_{\text {abd }}, \mathrm{H}-\mathrm{C}$ between the OVX and $\mathrm{OVX}+\mathrm{E}_{2}$ groups (Fig. 2a). In the dark phase, $T_{\mathrm{abd}}, \mathrm{H}-\mathrm{C}$ was greater in the OVX group than the $\mathrm{OVX}+\mathrm{E}_{2}$ group at $34{ }^{\circ} \mathrm{C}$ $\left(1.2 \pm 0.2\right.$ and $0.5 \pm 0.2{ }^{\circ} \mathrm{C}, P=0.001$; Fig. $\left.2 \mathrm{c}^{\prime}\right)$. In the OVX group, $T_{\text {abd }}, \mathrm{H}-\mathrm{C}$ was greater in the dark phase than the light phase at $34{ }^{\circ} \mathrm{C}(P<0.001)$. In addition, in the dark phase, $T_{\text {abd }}, \mathrm{H}-\mathrm{C}$ at $34{ }^{\circ} \mathrm{C}$ was greater than that at $28^{\circ} \mathrm{C}$ in the OVX group $(P=0.001)$.

In Experiment 2, there were significant effects of time $\left[P=0.014, F_{(2,32)}=4.88\right]$ and group $\left[P=0.001, F_{(3 \text {, }}\right.$ $\left.{ }_{16}=10.3\right]$ with a significant interaction between these two factors $\left[P<0.001, F_{(6,32)}=11.79\right]$. In the light phase, there were no differences in $T_{\text {abd }}, \mathrm{H}-\mathrm{C}$ between the $\mathrm{D}$ and $\mathrm{P}$ groups (Fig. 2b). In the dark phase, $T_{\mathrm{abd}}, \mathrm{H}-\mathrm{C}$ was greater in the $\mathrm{D}$ group than the $\mathrm{P}$ group at $31{ }^{\circ} \mathrm{C}(0.9 \pm 0.3$ and $0.3 \pm 0.0{ }^{\circ} \mathrm{C}$, respectively, $P=0.018$; Fig. $2 \mathrm{~d}$ ) and $34{ }^{\circ} \mathrm{C}\left(1.4 \pm 0.1\right.$ and $0.4 \pm 0.2^{\circ} \mathrm{C}$, respectively, $\left.P<0.001\right)$. In 
Table 2 Average measurements of the whole day and the light and dark phases and the circadian amplitude on the control day

\begin{tabular}{|c|c|c|c|c|}
\hline Group & $\begin{array}{l}\text { Average } \\
\text { of the whole } \\
\text { day }\end{array}$ & $\begin{array}{l}\text { Average } \\
\text { of the light } \\
\text { phase }\end{array}$ & $\begin{array}{l}\text { Average } \\
\text { of the dark } \\
\text { phase }\end{array}$ & Amplitude \\
\hline \multicolumn{5}{|l|}{$T_{\mathrm{abd} d}{ }^{\circ} \mathrm{C}$} \\
\hline OVX & $37.5 \pm 0.1$ & $37.3 \pm 0.1$ & $37.8 \pm 0.1^{\S}$ & $0.6 \pm 0.1$ \\
\hline $\mathrm{OVX}+\mathrm{E}_{2}$ & $37.6 \pm 0.1$ & $37.3 \pm 0.1$ & $37.9 \pm 0.1^{\S}$ & $0.6 \pm 0.1$ \\
\hline$D$ & $37.8 \pm 0.1$ & $37.4 \pm 0.1$ & $37.9 \pm 0.1^{\S}$ & $0.5 \pm 0.1$ \\
\hline$P$ & $37.6 \pm 0.1$ & $37.3 \pm 0.1$ & $37.9 \pm 0.1^{\S}$ & $0.6 \pm 0.1$ \\
\hline \multicolumn{5}{|l|}{$T_{\text {tail }}{ }^{\circ} \mathrm{C}$} \\
\hline OVX & $34.0 \pm 0.6$ & $34.4 \pm 0.4$ & $33.5 \pm 0.7$ & $0.9 \pm 0.3$ \\
\hline$O V X+E_{2}$ & $32.3 \pm 0.7$ & $33.8 \pm 0.5$ & $29.7 \pm 0.8^{* 5}$ & $3.4 \pm 0.7^{*}$ \\
\hline $\mathrm{D}$ & $34.6 \pm 0.3$ & $35.3 \pm 0.2$ & $34.0 \pm 0.4$ & $1.3 \pm 0.2$ \\
\hline$P$ & $33.7 \pm 0.3$ & $34.8 \pm 0.3$ & $32.7 \pm 0.3^{+\S}$ & $2.1 \pm 0.1^{\dagger}$ \\
\hline \multicolumn{5}{|c|}{ Spontaneous activity, au } \\
\hline ovx & $2.0 \pm 0.2$ & $1.1 \pm 0.2$ & $2.9 \pm 0.4^{\S}$ & $1.8 \pm 0.4$ \\
\hline$O V X+E_{2}$ & $2.4 \pm 0.4$ & $1.4 \pm 0.3$ & $3.3 \pm 0.5^{\S}$ & $1.8 \pm 0.3$ \\
\hline $\mathrm{D}$ & $1.5 \pm 0.4$ & $1.0 \pm 0.4$ & $2.7 \pm 0.3^{\S}$ & $1.8 \pm 0.2$ \\
\hline$P$ & $2.2 \pm 0.2$ & $1.2 \pm 0.2$ & $2.9 \pm 0.4^{\S}$ & $1.8 \pm 0.3$ \\
\hline \multicolumn{5}{|c|}{$\dot{\mathrm{V}} \mathrm{O}_{2}, \mathrm{ml} \mathrm{min} \min ^{-1} \mathrm{~kg} \mathrm{bw}^{-0.75}$} \\
\hline ovx & $15.1 \pm 0.3$ & $13.6 \pm 0.6$ & $16.5 \pm 0.9^{\S}$ & $3.3 \pm 1.3$ \\
\hline$O V X+E_{2}$ & $14.5 \pm 0.6$ & $12.1 \pm 0.9$ & $16.8 \pm 0.4^{\S}$ & $4.7 \pm 0.7$ \\
\hline $\mathrm{D}$ & $13.3 \pm 0.4$ & $12.4 \pm 0.7$ & $14.1 \pm 0.7^{\S}$ & $1.9 \pm 0.9$ \\
\hline$P$ & $14.7 \pm 0.3$ & $14.0 \pm 0.4$ & $15.4 \pm 0.7^{\S}$ & $1.6 \pm 0.9$ \\
\hline
\end{tabular}

Data are presented as means \pm standard error

OVX, ovariectomized; $E_{2}$, estradiol; $D$, control rats in the diestrus phase; $P_{r}$ control rats in the proestrus phase; $T_{\mathrm{a}}$, ambient temperature; $T_{\mathrm{abd}}$, abdominal temperature; $T_{\text {tail, }}$ tail skin temperature; bw, body weight; au, arbitrary unit

* Significant difference from the value in the OVX group, $P<0.05$

+ Significant difference from the value in the $D$ group, $P<0.05$

$\S$ Significant difference between the light and dark phases, $P<0.05$

the $\mathrm{D}$ group, $T_{\text {abd }}, \mathrm{H}-\mathrm{C}$ was greater in the dark phase than the light phase at $31{ }^{\circ} \mathrm{C}$ and $34{ }^{\circ} \mathrm{C}(P=0.02$ and $P<0.001$, respectively). In addition, in the dark phase, the $T_{\mathrm{abd}}, \mathrm{H}-\mathrm{C}$ at $31{ }^{\circ} \mathrm{C}$ and $34{ }^{\circ} \mathrm{C}$ were greater than that at $28^{\circ} \mathrm{C}$ in the $\mathrm{D}$ group $(P=0.001$ and $P<0.001$, respectively).

\section{$T_{\text {tail }}$ at $T_{\mathrm{a}}$ of $28^{\circ} \mathrm{C}, 31^{\circ} \mathrm{C}$, and $34^{\circ} \mathrm{C}$ in Experiments 1 and 2}

Figure 3 illustrates $T_{\text {tail }}$ in Experiments 1 and 2. The difference in $T_{\text {tail }}$ between the same period on the exposure and control day $\left(T_{\text {tail }}, \mathrm{H}-\mathrm{C}\right)$ is summarized in the same manner as $T_{\text {abd }}$ (Fig. 3a'-d). In Experiment 1, there was a significant effect of time $\left[P<0.001, F_{(2,48)}=15.04\right]$. In both phases, the $T_{\text {tail }}, \mathrm{H}-\mathrm{C}$ at $31^{\circ} \mathrm{C}$ and $34{ }^{\circ} \mathrm{C}$ was greater than that at $28{ }^{\circ} \mathrm{C}$ in the $\mathrm{OVX}$ and $\mathrm{OVX}+\mathrm{E}_{2}$ groups $\left(P<0.001\right.$, Fig. $3 \mathrm{a}^{\prime}$ and $\left.\mathrm{c}^{\prime}\right)$. In Experiment 2, there was a significant effect of time $\left[P<0.001, F_{(2,32)}=96.93\right]$. In the two phases, the $T_{\text {tail }}, \mathrm{H}-\mathrm{C}$ at $34{ }^{\circ} \mathrm{C}$ was higher than that at $28^{\circ} \mathrm{C}$ in the $\mathrm{D}$ and $\mathrm{P}$ groups $\left(P<0.001\right.$, Fig. $3 \mathrm{~b}^{\prime}$ and $\left.\mathrm{d}^{\prime}\right)$.
V $\mathrm{O}_{2}$ at $\mathrm{T}_{\mathrm{a}}$ of $28^{\circ} \mathrm{C}, 31^{\circ} \mathrm{C}$, and $34^{\circ} \mathrm{C}$ in Experiments 1 and 2 Figure 4 indicates $\dot{\mathrm{VO}}_{2}$ in Experiments 1 and 2. The difference in $\dot{\mathrm{VO}}_{2}$ between the same period on the exposure and control days $\left(\dot{\mathrm{VO}}_{2}, \mathrm{H}-\mathrm{C}\right)$ is summarized in the same manner as $T_{\text {abd }}$ (Fig. $4 \mathrm{a}^{\prime}-\mathrm{d}$ ). In Experiment 1 , there were significant effects of time $\left[P<0.001, F_{(2}\right.$, $\left.{ }_{48)}=21.40\right]$ and group $\left[P=0.038, F_{(3,24)}=3.28\right]$ with a significant interaction between these two factors $\left[P=0.006, F_{(6,48)}=3.49\right]$. In the light phase, the $\dot{\mathrm{VO}}_{2}$, $\mathrm{H}-\mathrm{C}$ at $31{ }^{\circ} \mathrm{C}$ and $34{ }^{\circ} \mathrm{C}$ was smaller than that at $28{ }^{\circ} \mathrm{C}$ in the OVX and OVX $+\mathrm{E}_{2}$ groups $\left(P<0.05\right.$, Fig. $\left.4 \mathrm{a}^{\prime}\right)$. In the dark phase, the $\dot{\mathrm{VO}}_{2}, \mathrm{H}-\mathrm{C}$ was smaller in the $\mathrm{OVX}+\mathrm{E}_{2}$ group than the OVX group at $34{ }^{\circ} \mathrm{C}(-3.1 \pm 2.3$ and $-7.6 \pm 2.5 \mathrm{ml} \mathrm{min}^{-1} \mathrm{~kg}$ body weight ${ }^{-0.75}, P=0.023$, Fig. $\left.4 c^{\prime}\right)$. In the OVX $+\mathrm{E}_{2}$ group, the $\dot{\mathrm{VO}}_{2}, \mathrm{H}-\mathrm{C}$ was smaller in the dark phase than the light phase at $34{ }^{\circ} \mathrm{C}$ $(P=0.014)$. In addition, in the dark phase, the $\dot{\mathrm{VO}}_{2}, \mathrm{H}-\mathrm{C}$ at $31{ }^{\circ} \mathrm{C}$ and $34{ }^{\circ} \mathrm{C}$ was smaller than that at $28{ }^{\circ} \mathrm{C}$ in the $\mathrm{OVX}+\mathrm{E}_{2}$ group $(P=0.022$ and $P<0.001$, respectively).

In Experiment 2, there were significant effects of time $\left[P<0.001, F_{(2,32)}=10.02\right]$ and group $[P<0.001$, $\left.F_{(3,16)}=17.08\right]$. In addition, a significant interaction between these two factors was observed $\left[P=0.034, F_{(6}\right.$, $32)=2.63]$. In the light phase, there were no differences in the $\dot{\mathrm{VO}}_{2}, \mathrm{H}-\mathrm{C}$ between the $\mathrm{D}$ and $\mathrm{P}$ groups (Fig. 4b). In the dark phase, the $\dot{\mathrm{VO}}_{2}, \mathrm{H}-\mathrm{C}$ was smaller in the $\mathrm{P}$ group than the $\mathrm{D}$ group at $34{ }^{\circ} \mathrm{C}(-6.7 \pm 0.8$ and $-10.7 \pm 2.5 \mathrm{ml} \mathrm{min}^{-1} \mathrm{~kg}$ body weight ${ }^{-0.75}, P=0.019$, Fig. $\left.4 d^{\prime}\right)$. In the $\mathrm{D}$ group, the $\mathrm{VO}_{2}, \mathrm{H}-\mathrm{C}$ was smaller in the dark phase than the light phase at a $T_{\mathrm{a}}$ of $31{ }^{\circ} \mathrm{C}$ and $34{ }^{\circ} \mathrm{C}(P=0.017$ and $P=0.003$, respectively $)$. In the $\mathrm{P}$ group, the $\dot{\mathrm{V}} \mathrm{O}_{2}, \mathrm{H}-\mathrm{C}$ was smaller in the dark phase than the light phase at $34{ }^{\circ} \mathrm{C}(P<0.001)$. In addition, in the dark phase, the $\dot{\mathrm{VO}}_{2}, \mathrm{H}-\mathrm{C}$ was smaller at $31^{\circ} \mathrm{C}$ and $34{ }^{\circ} \mathrm{C}$ than a $T_{\mathrm{a}}$ of $28{ }^{\circ} \mathrm{C}$ in the $\mathrm{P}$ group $(P=0.028$ and $P<0.001$, respectively).

\section{Spontaneous activity during the exposure at $28-34{ }^{\circ} \mathrm{C}$ in Experiments 1 and 2}

Spontaneous activity did not change from that on the control day. There were no differences among the four groups in each phase.

\section{Heat loss index of the tail}

The heat loss index of the tail at each $T_{\mathrm{a}}$ in Experiments 1 and 2 is summarized in Fig. 5a-d. In Experiment 1 , there were significant effects of time $\left[P<0.001, F_{(3}\right.$, $\left.{ }_{72)}=37.56\right]$ and group $\left[P<0.001, F_{(3,24)}=19.50\right]$. In both phases, the heat loss index at $28-34{ }^{\circ} \mathrm{C}$ was higher than that at $25{ }^{\circ} \mathrm{C}$ in both groups $(P<0.05)$. There were no significant differences between the two groups. In the 


\section{$\mathrm{T}_{\mathrm{abd}}$}

light phase

dark phase

\section{Experiment 1}
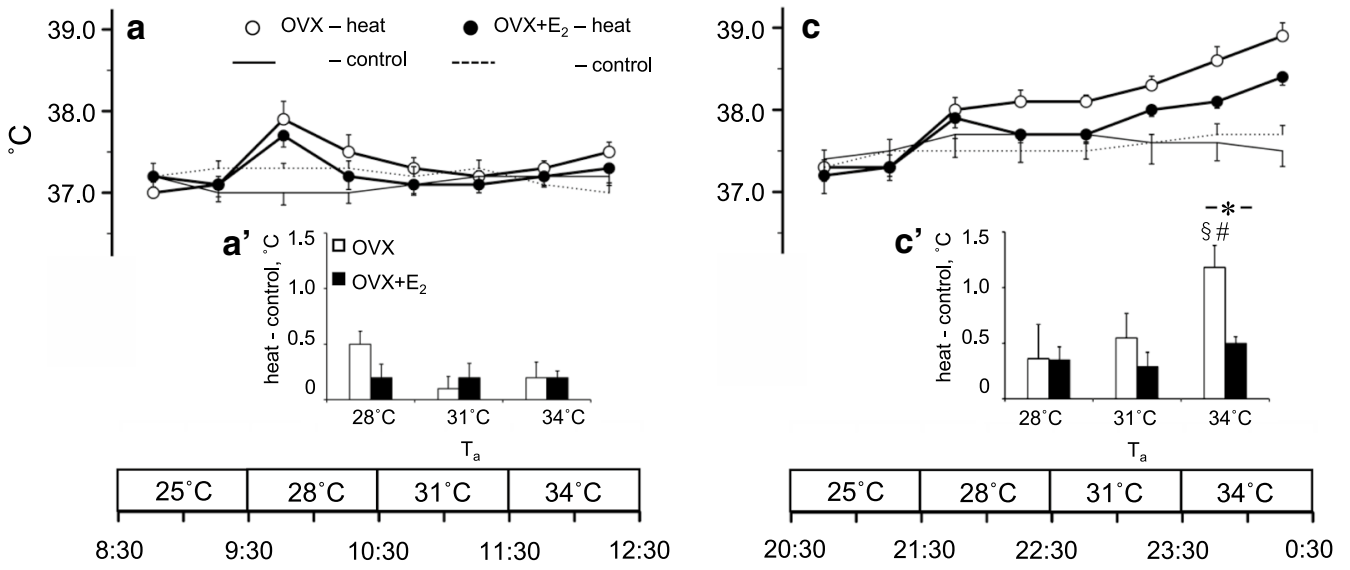

\section{Experiment 2}
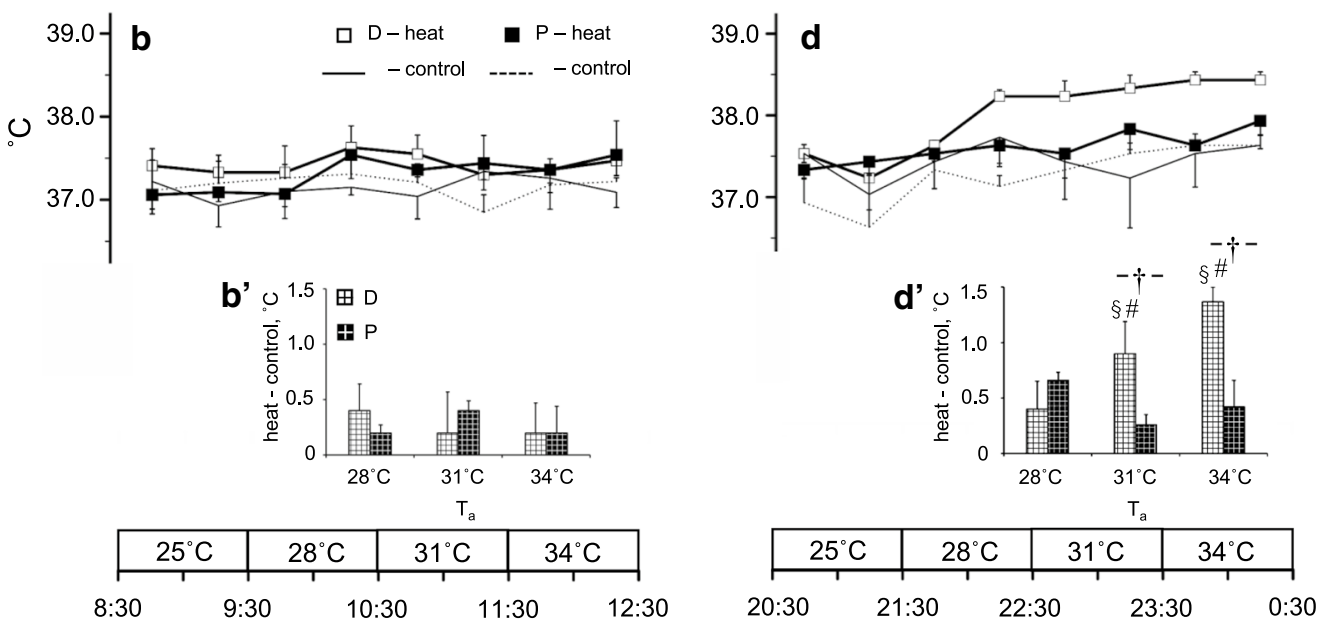

Time of day, $h$

Fig. 2 Abdominal temperature $\left(T_{\text {abd }}\right)$ during heat exposure in the ovariectomized $(O V X)$ and $O V X+$ estradiol $\left(E_{2}\right)$ groups (open and closed circles, respectively) in the light (a) and dark (c) phases, and in the D and P groups (open and closed squares, respectively) in the light (b) and dark (d) phases. The control data are indicated by solid and dashed lines without symbols (OVX and OVX $+E_{2}$ groups in $\mathbf{a}$ and $\mathbf{c}$, respectively, and $D$ and $P$ groups in $\mathbf{b}$ and $\mathbf{d}$, respectively). Differences in $T_{\text {abd }}$ at the same time of day between the heat exposure and control days are presented as $\mathrm{H}-\mathrm{C}$ $\left(\mathbf{a}^{\prime}-\mathbf{d}^{\prime}\right.$ in the light and dark phases in Experiments 1 and 2, respectively). Data are presented as means \pm standard error ( $\mathbf{a}$ and $\mathbf{c}, n=7$ in each group; $\mathbf{b}$ and $\mathbf{d}, n=5$ in each group). * Significant difference between the $\mathrm{OVX}$ and $\mathrm{OVX}+\mathrm{E}_{2}$ groups $(P<0.05)$. ${ }^{\dagger}$ Significant difference between the $\mathrm{D}$ and $P$ groups $(P<0.05)$. ${ }^{5}$ Significant difference between the light and dark phases $(P<0.05)$. "Significant difference from the value at an ambient temperature $\left(T_{a}\right)$ of $28^{\circ} \mathrm{C}(P<0.05)$. D, control rats in the diestrus phase; $P$, control rats in the proestrus phase 
$T_{\text {tail }}$

light phase

\section{Experiment 1}
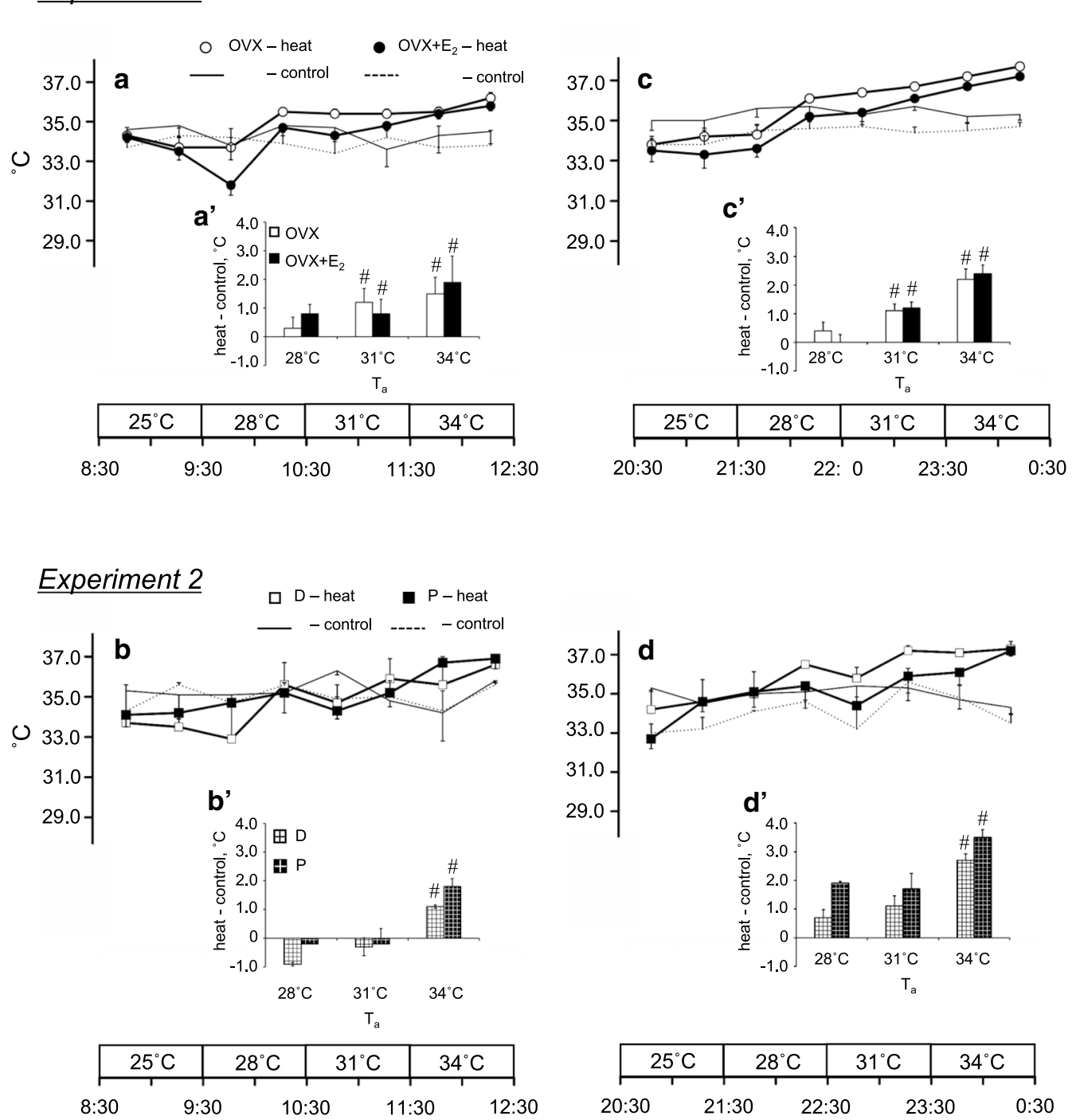

dark phase


Time of day, $\mathrm{h}$

Fig. 3 Tail skin temperature $\left(T_{\text {tail }}\right)$ during heat exposure in the ovariectomized $(O V X)$ and $O V X+$ estradiol $\left(E_{2}\right)$ groups (open and closed circles, respectively) in the light (a) and dark (c) phases, and in the D and $P$ groups (open and closed squares, respectively) in the light (b) and dark (d) phases. The control data are indicated by solid and dashed lines without symbols (OVX and OVX $+E_{2}$ groups in $\mathbf{a}$ and $\mathbf{c}$, respectively, and $D$ and $P$ groups in $\mathbf{b}$ and $\mathbf{d}$, respectively). Differences in $T_{\text {tail }}$ at the same time of day between the heat exposure and control days are presented as $\mathrm{H}-\mathrm{C}\left(\mathbf{a}^{\prime}-\mathbf{d}^{\prime}\right.$ in the light and dark phases in Experiments 1 and 2, respectively). Data are presented as means \pm standard error ( $\mathbf{a}$ and $\mathbf{c}, n=7$ in each group; $\mathbf{b}$ and d, $n=5$ in each group). "Significant difference from the value at an ambient temperature $\left(T_{a}\right)$ of $28^{\circ} \mathrm{C}(P<0.05)$. D, control rats in the diestrus phase; $\mathrm{P}$, control rats in the proestrus phase

$\mathrm{OVX}+\mathrm{E}_{2}$ group, the heat loss index at $28-34{ }^{\circ} \mathrm{C}$ was higher in the dark phase than the light phase $(P<0.001)$.

In Experiment 2, there were significant effects of time $\left[P<0.001, F_{(3,48)}=24.51\right]$ and group $\left[P<0.001, F_{(3}\right.$,
16) $=20.90]$. In the two phases, the heat loss index at $28-34{ }^{\circ} \mathrm{C}$ was higher than that at $25^{\circ} \mathrm{C}(P<0.01)$ in both groups. No significant differences were found between the two groups. In both the $\mathrm{D}$ and $\mathrm{P}$ groups, the heat loss 


\section{$\dot{\mathrm{VO}}_{2}$}

\section{dark phase}

\section{Experiment 1}
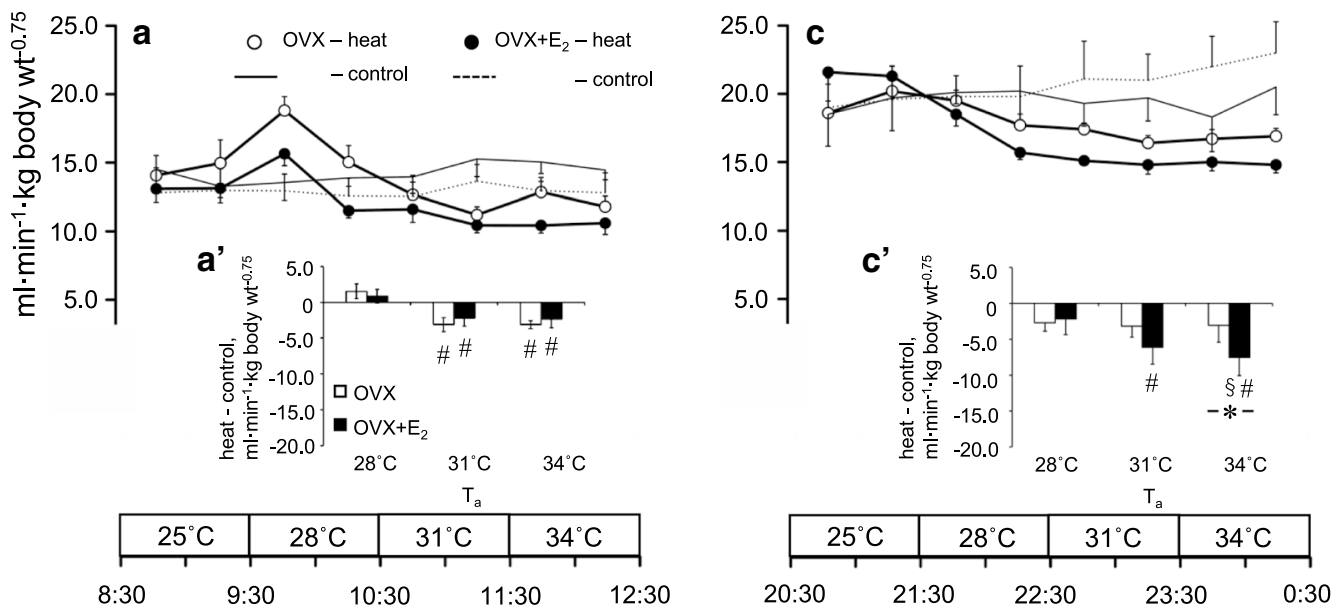

\section{Experiment 2}
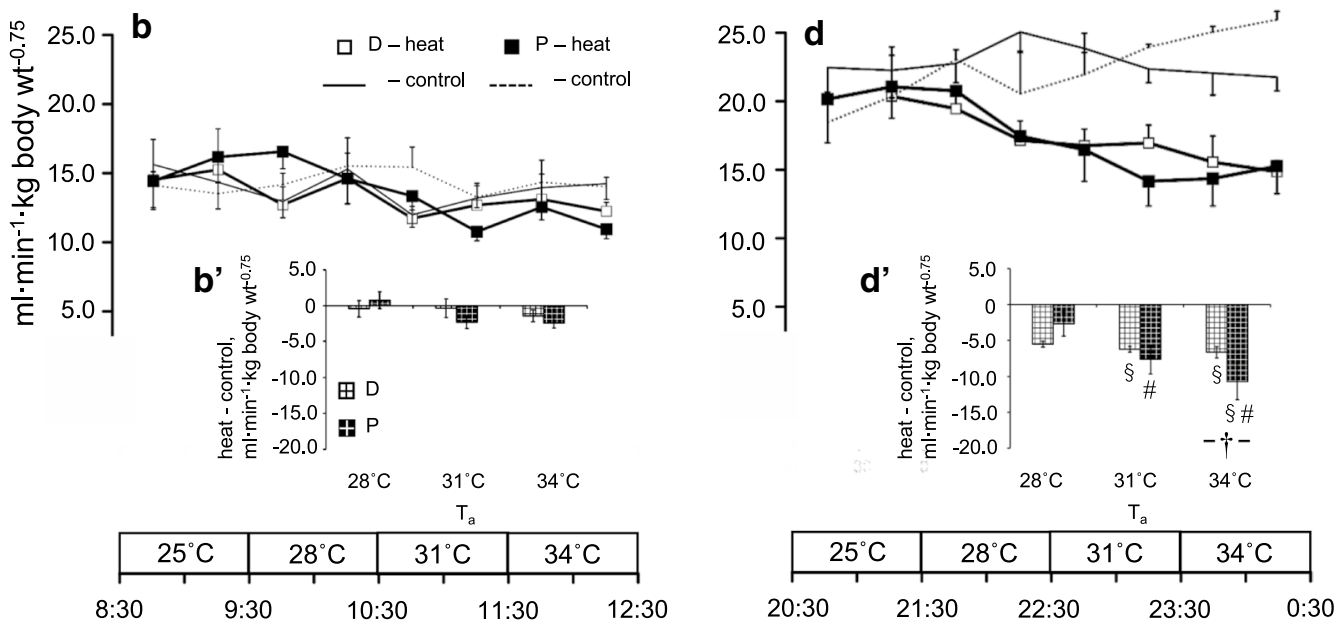

Time of day, $\mathrm{h}$

Fig. 4 Oxygen consumption $\left(\mathrm{V}_{2}\right)$ during heat exposure in the ovariectomized $(\mathrm{OVX})$ and $\mathrm{OVX}+$ estradiol $\left(\mathrm{E}_{2}\right)$ groups (open and closed circles, respectively) in the light (a) and dark (c) phases, and in the D and P groups (open and closed squares, respectively) in the light (b) and dark (d) phases. The control data are indicated by solid and dashed lines without symbols (OVX and OVX $+E_{2}$ groups in $\mathbf{a}$ and $\mathbf{c}$, respectively, and D and $\mathrm{P}$ groups in $\mathbf{b}$ and $\mathbf{d}$, respectively). Differences in $\dot{\mathrm{V}}_{2}$ at the same time of day between the heat exposure and control days are presented as $\mathrm{H}-\mathrm{C}$ ( $\mathbf{a}^{\prime}-\mathbf{d}^{\prime}$ in the light and dark phases in Experiments 1 and 2, respectively). Data are presented as means \pm standard error ( $\mathbf{a}$ and $\mathbf{c}, \mathrm{n}=7$ in each group; $\mathbf{b}$ and $\mathbf{d}, n=5$ in each group). *Significant difference between the OVX and $\mathrm{OVX}+\mathrm{E}_{2}$ groups $(P<0.05)$. ${ }^{\dagger}$ Significant difference between the $\mathrm{D}$ and $P$ groups $(P<0.05)$. ${ }^{\circledR}$ Significant difference between the light and dark phases $(P<0.05)$. "Significant difference from the value at an ambient temperature $\left(T_{a}\right)$ of $28^{\circ} \mathrm{C}(P<0.05)$. D, control rats in the diestrus phase; $P$, control rats in the proestrus phase 


\section{Heat loss index of the tail}

\section{Experiment 1}
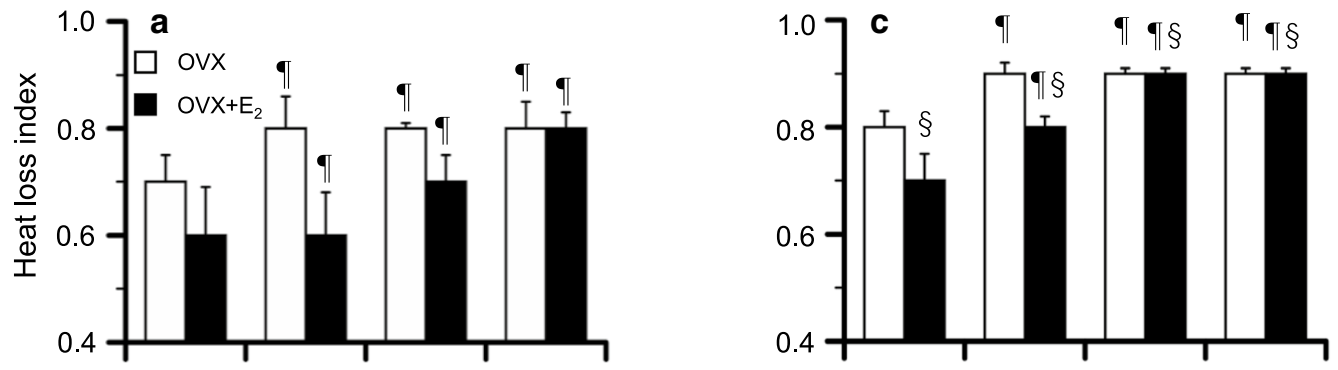

\section{Experiment 2}

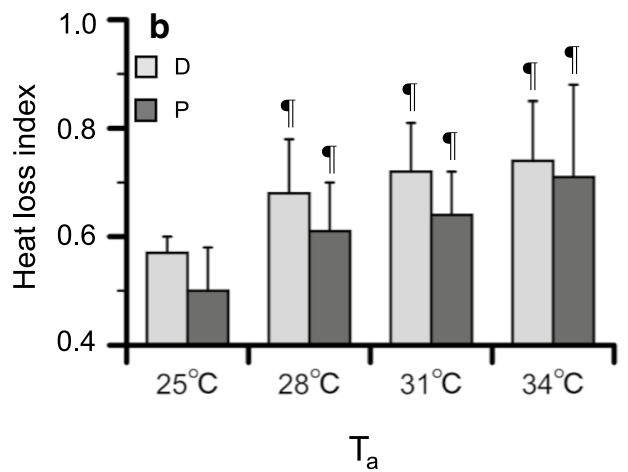

light phase

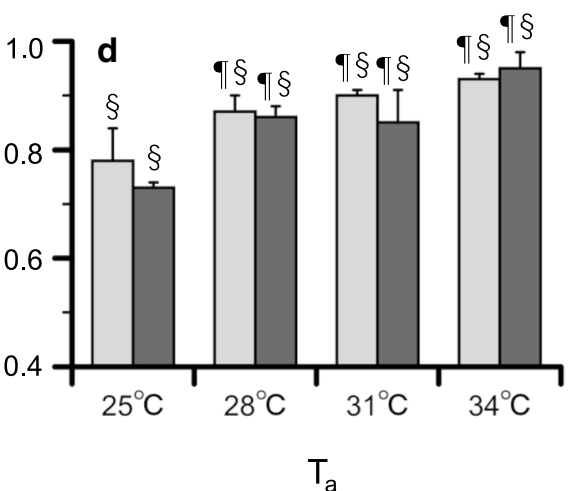

dark phase

Fig. 5 The heat loss index of the tail during heat exposure in the ovariectomized (OVX) and OVX + estradiol ( $\left.E_{2}\right)$ groups in the light (a) and dark (c) phases, and in the D and P groups in the light (b) and dark (d) phases. The heat loss index is presented as the $1 \mathrm{~h}$ average for each ambient temperature $\left(T_{a}\right)$. Data are presented as means \pm standard error ( $n=5$ in each group). ${ }^{\S}$ Significant difference between the light and dark phases $(P<0.05)$. "Significant difference from the value at a $T_{a}$ of $25^{\circ} \mathrm{C}(P<0.05)$. D, control rats in the diestrus phase; $P$, control rats in the proestrus phase

index was higher in the dark phase than the light phase $(P<0.001)$.

\section{Thermal conductance of the whole body}

The thermal conductance of the whole body in Experiments 1 and 2 is illustrated in Fig. 6a-d. In Experiment 1 , there were significant effects of time $[P<0.001$, $\left.F_{(3,72)}=45.94\right]$ and group $\left[P=0.008, F_{(3,24)}=5.00\right]$. In the light and dark phases, the thermal conductance at $28-34{ }^{\circ} \mathrm{C}$ was higher than that at $25{ }^{\circ} \mathrm{C}$ in both groups $(P<0.001$, Fig. 6a, c). No significant differences were observed between the two groups in each phase.

In Experiment 2, there was a significant effect of time $\left[P<0.001, F_{(3,48)}=30.42\right]$. In both phases, the thermal conductance at $28-34{ }^{\circ} \mathrm{C}$ was higher than that at $25{ }^{\circ} \mathrm{C}$ $(P<0.01$, Fig. $6 \mathrm{~b}, \mathrm{~d})$ in both groups. There were no significant differences between the two groups in each phase.

\section{Discussion}

In the present study, we found that a higher level of plasma $E_{2}$, which was observed in the $O V X+E_{2}$ and $P$ groups, which may activate thermoregulatory responses during exposure to $34{ }^{\circ} \mathrm{C}$ heat and prevent increases in $T_{\text {abd }}$. However, such influence of $\mathrm{E}_{2}$ was observed only in the dark phase. In addition, attenuated metabolism in response to heat may be involved in the mechanism underlying the influence of $\mathrm{E}_{2}$.

\section{Body weight}

It has been reported that ovariectomy augments increase in body weight, which is suppressed by $E_{2}$ replacement [21-25]. In the present study, there were no differences in the final body weight in both phases 


\section{Thermal conductance of the whole body}

\section{Experiment 1}
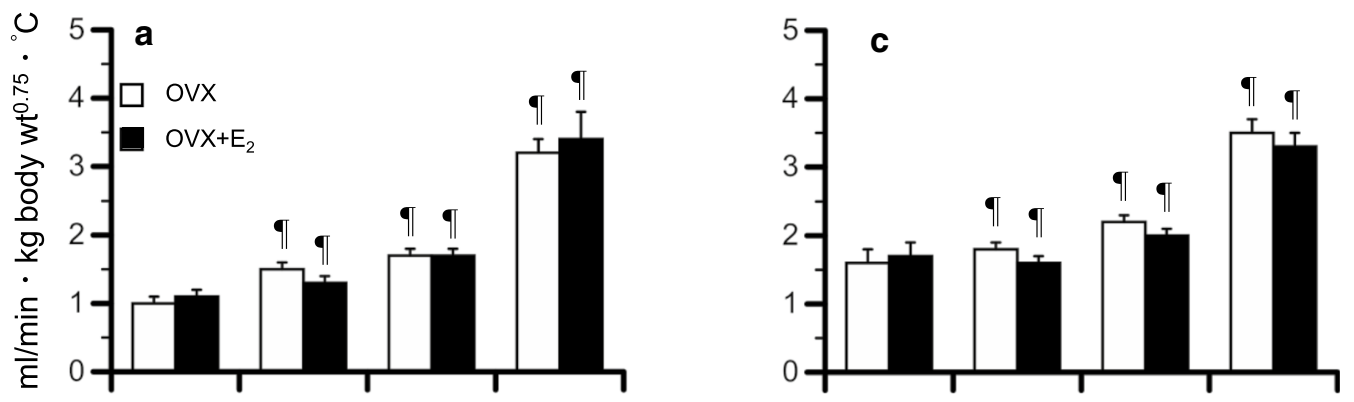

\section{Experiment 2}

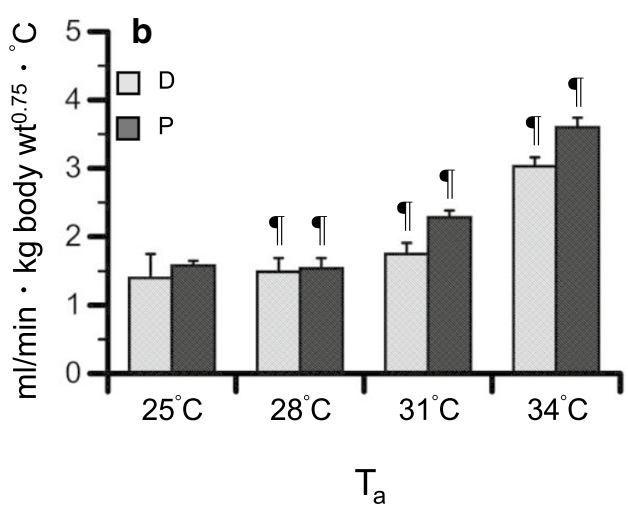

light phase

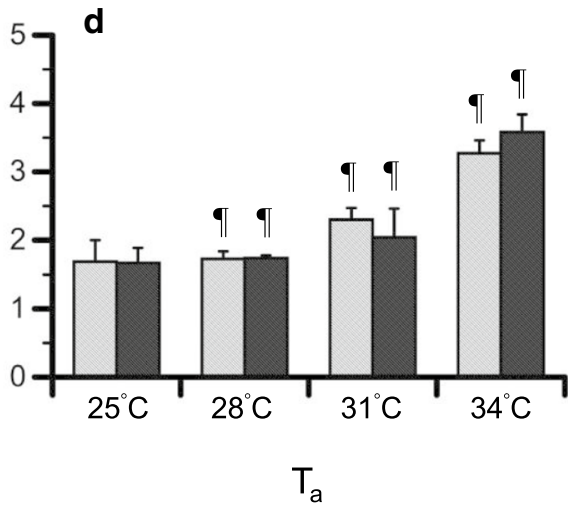

dark phase

Fig. 6 The thermal conductance of the whole body during heat exposure in the ovariectomized $(\mathrm{OVX})$ and $\mathrm{OVX}+$ estradiol $\left(\mathrm{E}_{2}\right)$ groups in the light (a) and dark (c) phases, and in the D and P groups in the light (b) and dark (d) phases. The thermal conductance is presented as the $1 \mathrm{~h}$ average for each ambient temperature $\left(T_{\mathrm{a}}\right)$. Data are presented as means \pm standard error ( $n=5$ in each group). "Significant difference from the value at a $T_{\mathrm{a}}$ of $25^{\circ} \mathrm{C}(P<0.05)$. $D$, control rats in the diestrus phase; $P$, control rats in the proestrus phase

between the OVX and OVX $+\mathrm{E}_{2}$ groups (Table 1). One possible reason is the variation of the initial body weight due to difference in the recovery period from the surgery (Table 1). Another reason may be that the duration of the $E_{2}$ treatment may not have been long enough to influence body weight. It has been reported that the influence becomes apparent more than 4-5 weeks after the initiation of the $\mathrm{E}_{2}$ treatment $[21,22]$.

$T_{\text {abd }}, T_{\text {tail }}$, spontaneous activity, and $\dot{\mathrm{VO}}_{2}$ on the control day In both Experiments 1 and 2, rats with higher level of plasma $E_{2}$ (i.e., the $\mathrm{OVX}+\mathrm{E}_{2}$ and $\mathrm{P}$ groups) exhibited a lower $T_{\text {tail }}$ than the other groups only in the dark phase. However, this difference was not observed in $T_{\text {abd }}$, spontaneous activity, or $\dot{\mathrm{V}}_{2}$ (Table 2). $T_{\text {abd }}$ became higher in the middle of the dark phase in the OVX $+\mathrm{E}_{2}$ rats, which may have reflected lower $T_{\text {tail }}$ (i.e., attenuated heat loss). Although no statistical difference in the amplitude of $\dot{\mathrm{VO}}_{2}, \mathrm{E}_{2}$ may also increase $\dot{\mathrm{V}} \mathrm{O}_{2}$ in the dark phase, resulting in grater $T_{\text {abd }}$. As previously reported [11], $E_{2}$ increased $T_{\text {abd }}$ in OVX rats in the dark phase and $T_{\text {tail }}$ inversely decreased (Fig. 1a, c). The result suggests difference in thermoregulatory control between the OVX and OVX $+\mathrm{E}_{2}$ groups even in the control condition. However, we did not find such difference between the $\mathrm{P}$ and $\mathrm{D}$ groups. This may be due to higher progesterone level in the $\mathrm{P}$ and $\mathrm{D}$ groups as previously reported [26]. Stachenfeld et al. [27] reported that the 
effect of $E_{2}$ on thermoregulation is reversed by the presence of progesterone.

Previous studies have also reported an involvement of $\mathrm{E}_{2}$ in $T_{\text {tail }}$, reflecting tail blood flow [11, 20, 28, 29]. However, the difference between the light and dark phases has not been well examined. In the present study, the OVX $+E_{2}$ and $P$ groups exhibited a higher level of plasma $E_{2}$ than the other groups without any difference between the light and dark phases (Table 1). Only one study has reported a phase difference in the $\mathrm{P}$ phase, finding that the $E_{2}$ level was lower in the early dark phase than the light phase [30]. Thus, at a $T_{\mathrm{a}}$ of $25^{\circ} \mathrm{C}$, the influence of $\mathrm{E}_{2}$ on $T_{\text {tail }}$ may be modulated by the circadian phases.

Nagashima et al. [31] reported that the skin temperature of each part of the tail, as assessed by infrared thermography, reflects the heat loss response. This suggests that the $T_{\text {tail }}$ data were reliable in evaluating heat loss in the present study. More importantly, the procedure does not disturb tail movement [11], which largely affects heat loss from the tail [32].

\section{Responses to the exposure at $T_{\mathrm{a}}$ of $28^{\circ} \mathrm{C}, 31^{\circ} \mathrm{C}$, and $34^{\circ} \mathrm{C}$ in the light phase}

When rats are exposed to heat, heat loss processes are activated, such as vasodilation of the tail [33], salivaspreading, grooming $[6,34,35]$, posture change [36], and metabolism reduction $[7,8]$. In this study, the heat loss index of the tail similarly increased from that at a $T_{\mathrm{a}}$ of $25^{\circ} \mathrm{C}$ in each group in Experiments 1 and 2 (Fig. 5a, b). In addition, the thermal conductance of the whole body also similarly increased from that at a $T_{\mathrm{a}}$ of $25^{\circ} \mathrm{C}$ in all groups (Fig. 6a, b). It was reported that, in rats, evaporative heat loss mechanism was activated when $T_{\mathrm{a}}$ surpasses of $34{ }^{\circ} \mathrm{C}$ [6]. Therefore, saliva-spreading and grooming may not be involved in the increase in the thermal conductance for the whole body. Moreover, $E_{2}$ had no influence on the responses.

In Experiment 1, a similar reduction of $\dot{\mathrm{VO}}_{2}$ from the control level was observed at a $T_{\mathrm{a}}$ of $31{ }^{\circ} \mathrm{C}$ and $34{ }^{\circ} \mathrm{C}$ in the OVX and OVX $+\mathrm{E}_{2}$ groups (Fig. 4a). It was reported that, in rats, the spontaneous activity decreased in $42{ }^{\circ} \mathrm{C}$ heat [9]. However, spontaneous activity did not change in the present study, suggesting that activity was not involved in the mechanism.

$\dot{\mathrm{V}}_{2}$ did not change in the $\mathrm{P}$ and $\mathrm{D}$ groups in Experiment 2. The difference from the result in Experiment 1 might be due to the higher progesterone level in the $\mathrm{P}$ and D groups. Uchida et al. [26] reported lower levels of plasma progesterone in OVX and OVX $+\mathrm{E}_{2}$ rats and a higher level in control rats in both the $\mathrm{P}$ and $\mathrm{D}$ phases. The difference would be because progesterone is secreted from the ovary. Nolan and Proietto [37] demonstrated that progesterone increased glucose uptake in the brown fat, which is associated with metabolic heat production. Thus, the higher progesterone level in the control rats may have maintained a greater $\mathrm{VO}_{2}$ in the heat in a part.

\section{Responses to the exposure at $T_{\mathrm{a}}$ of $28^{\circ} \mathrm{C}, 31^{\circ} \mathrm{C}$, and $34^{\circ} \mathrm{C}$ in the dark phase}

$T_{\text {abd }}$ in the OVX and D groups was higher at $31{ }^{\circ} \mathrm{C}$ and $34{ }^{\circ} \mathrm{C}$ than at $28^{\circ} \mathrm{C}$; however, no changes were observed in the OVX $+E_{2}$ and $P$ groups (Fig. 2c, d). These results suggest the involvement of $E_{2}$ in thermoregulation in response to heat. It was reported that $E_{2}$ induces shift in thermoneutral zone to lower ambient temperature [2]. Thus, even the same $T_{\mathrm{a}}$ may have given greater thermal load to the OVX and D groups, increasing $T_{\mathrm{abd}}$.

$T_{\text {abd }}$ and $T_{\text {tail }}$ at 20:30-0:30 (Fig. 1) was different from those on the control day in Experiments 1 and 2 (Figs. 2 and 3). One possible reason is that the data were assessed in the home cages, but the data on the control day were obtained in the Plexiglas box in the climatic chamber.

In Experiment 1, heat loss responses, as assessed by the heat loss index of the tail and thermal conductance of the whole body, similarly increased in both groups (Figs. 5c and $6 \mathrm{c}$ ). Therefore, heat loss responses do not explain for the increase of $T_{\text {abd }}$ in the OVX and D groups.

$\dot{\mathrm{VO}}_{2}$ decreased from the control day only in the OVX $+E_{2}$ group (Fig. 4c'). Because spontaneous activity was similar between the two groups, we concluded that activity was not involved in the mechanism. Several studies have reported that estrogen reduces energy intake $[23,38,39]$. Therefore, food deprivation during the heat exposure period may have caused the reduction in $\dot{\mathrm{VO}}_{2}$ via $E_{2}$ in a part. However, this influence of $E_{2}$ on energy intake may be small in the dark phase based on the findings of previous studies [24, 25]. Thus, we assume that the reduction in $\dot{\mathrm{VO}}_{2}$ was caused by the direct influence of the heat as part of the thermoregulatory responses. In addition, $E_{2}$ may be involved in the mechanism. We did not assess ventilation in the present study, which may affect $\dot{\mathrm{VO}}_{2}$ and/or evaporative heat loss. Marques et al. $[40,41]$ reported that OVX rats showed lower ventilation only when either hypoxic or hypercapnia was applied. In addition, both $E_{2}$ and $P$ was not involved in the mechanism. Thus, we assume that $E_{2}$ does not affect ventilation in heat. The mechanism underlying the difference in the reduction in $\dot{\mathrm{V}} \mathrm{O}_{2}$ between the light and dark phases remains unclear, despite the similar levels of plasma $E_{2}$ between phases. One possible reason is that $\dot{\mathrm{VO}}_{2}$ was sufficiently low in the light phase, which could not be a factor increasing $T_{\mathrm{abd}}$ in the heat.

We also found a similar increase in the heat loss index of the tail and the thermal conductance of the whole body in in the P and D groups in Experiment 2 (Figs. 5d and 
$6 \mathrm{~d})$. It was reported that progesterone has no influence on the tail skin temperature under ambient conditions [11]. Therefore, these results indicate that $E_{2}$ and progesterone have no influence on the heat loss responses. In addition, we observed a difference in the reduction in $\dot{\mathrm{VO}}_{2}$ between the $\mathrm{D}$ and $\mathrm{P}$ groups in the dark phase (Fig. $4 d^{\prime}$ ).

There are differences in the thermoregulatory responses between the $\mathrm{OVX}+\mathrm{E}_{2}$ and $\mathrm{P}$ groups, suggesting the influence of progesterone. $T_{\text {abd }}$ increased at $T_{\mathrm{a}}$ of $31{ }^{\circ} \mathrm{C}$ in the P group. At $T_{\mathrm{a}}$ of $31{ }^{\circ} \mathrm{C}, T_{\text {tail }}$ did not increase in both the $\mathrm{P}$ and $\mathrm{D}$ groups but increased in the $\mathrm{OVX}+\mathrm{E}_{2}$ group. It was reported that progesterone per se increases body temperature; however, $\mathrm{E}_{2}$ reduces the effect [27]. Thus, even at $T_{\mathrm{a}}$ of $31^{\circ} \mathrm{C}$, the $\mathrm{D}$ group may not be able to control body temperature.

Previous study in rats reported a reduction of plasma thyroid stimulating hormones 7 days after $34{ }^{\circ} \mathrm{C}$ exposure [7]. Thus, thyroid function may be involved in the mechanism for the reduction of metabolism. However, we did not assess the thyroid function as well as the influence of $E_{2}$. Thus, the mechanism remains unclear and needs to be clarified in future study.

\section{Conclusions}

The present study suggests that, in both ovariectomized and control rats, a higher level of plasma $E_{2}$ activates thermoregulatory responses to mild heat at $34{ }^{\circ} \mathrm{C}$ only in the dark phase. In addition, the decrease in metabolism in response to heat may be involved in the mechanism. The present study is the first to demonstrate the influence of $E_{2}$ on metabolism as part of the thermoregulatory response to heat and the interaction with the circadian phase. However, the modulation of the metabolic response to heat by $\mathrm{E}_{2}$ remains unclear. This mechanism should be clarified in future studies. Moreover, our findings suggest that postmenopausal women experience reduced thermoregulation even in mild heat and are at higher risk of heat-related health problems.

\begin{abstract}
Abbreviations
ANOVA: Analysis of variance; D: Diestrus; $\mathrm{E}_{2}$ : Estradiol; OVX: Ovariectomized; $\mathrm{P}$ : Proestrus; $T_{\mathrm{a}}$ : Ambient temperature; $T_{\text {abd: }}$ : Abdominal temperature; $T_{\text {tail }}$ 'Tail skin temperature; $\dot{V}_{2}$ : Oxygen consumption.
\end{abstract}

\section{Acknowledgements}

Not applicable.

\section{Authors' contributions}

KN supervised the entire project. SM and KN designed the study and wrote the manuscript. SM, YM, and IK conducted the experiments. All authors read and approved the final manuscript.

\section{Funding}

This work was supported by JSPS KAKENHI Grant Numbers No. 16K13055, No. 18H06420; Japan and Advanced Research Center for Human Sciences, Waseda University.

\section{Availability of data and materials}

The datasets used and/or analyzed during the current study are available from the corresponding author on reasonable request.

\section{Ethics approval and consent to participate}

All animal experiments and care were conducted in accordance with the institutional guidelines, which follow the Fundamental Guidelines for Proper Conduct of Animal Experiments and Related Activities in Academic Research Institutions under the jurisdiction of the Ministry of Education, Culture, Sports, Science, and Technology (Notice No. 71, 2006; Tokyo, Japan). The Institutional Animal Care and Use Committee of Waseda University (Tokyo, Japan) approved all experimental procedures applied in the present study (Approval no. A071).

\section{Consent for publication}

Not applicable.

\section{Competing interests}

The authors declare that they have no competing interests.

\section{Author details}

${ }^{1}$ Body Temperature and Fluid Laboratory, Faculty of Human Sciences, Waseda University, Mikajima 2-579-15, Tokorozawa, Saitama 359-1192, Japan. ${ }^{2}$ Graduate School of Human Sciences, Faculty of Human Sciences, Waseda University, Tokorozawa, Japan.

Received: 22 June 2020 Accepted: 11 November 2020

Published online: 30 November 2020

\section{References}

1. Baker MA, Dawson DD, Peters CE, Walker AM (1994) Effects of estrogen on thermoregulatory evaporation in rats exposed to heat. Am J Physiol 267:R673-R677

2. Dacks PA, Rance NE (2010) Effects of estradiol on the thermoneutral zone and core temperature in ovariectomized rats. Endocrinology 151:11871193. https://doi.org/10.1210/en.2009-1112

3. Hosono T, Chen X-M, Miyatsuji A et al (2001) Effects of estrogen on thermoregulatory tail vasomotion and heat-escape behavior in freely moving female rats. Am J Physiol Regul Integr Comp Physiol 280:R1341-1347

4. Hosono T, Chen XM, Zhang YH, Kanosue K (1997) Effects of estrogen on thermoregulatory responses in freely moving female rats. Ann NY Acad Sci 813:207-210

5. Krajewski-Hall SJ, Blackmore EM, McMinn JR, Rance NE (2018) Estradiol alters body temperature regulation in the female mouse. Temperature 5:56-69. https://doi.org/10.1080/23328940.2017.1384090

6. Hainsworth F (1968) Evaporative water loss from rats in the heat. Am J Physiol Content 214:979-982. https://doi.org/10.1152/ajple gacy.1968.214.5.979

7. Rousset B, Cure M, Jordan D et al (1984) Metabolic alterations induced by chronic heat exposure in the rat: the involvement of thyroid function. Pflügers Arch Eur J Physiol 401:64-70. https://doi.org/10.1007/BF005 81534

8. Bobek S, Niezgoda J, Pietras M et al (1980) The effect of acute cold and warm ambient temperatures on the thyroid hormone concentration in blood plasma, blood supply, and oxygen consumption in Japanese quail. Gen Comp Endocrinol 40:201-210. https://doi.org/10.1016/00166480(80)90123-9

9. Clark RV (1971) Behavioral thermoregulation by the white rat at high ambient temperatures. J Exp Zool 178:387-392. https://doi.org/10.1002/ jez.1401780314

10. Marui S, Uchida Y, Nagashima K (2016) Daily changes of body temperature and heart rate are modulated after estradiol depletion in female rats. Anat Physiol 06:1-7. https://doi.org/10.4172/2161-0940.1000197

11. Williams H, Dacks PA, Rance NE (2010) An improved method for recording tail skin temperature in the rat reveals changes during the estrous cycle and effects of ovarian steroids. Endocrinology 151:5389-5394. https://doi. org/10.1210/en.2010-0630

12. Cosmi S, Pawlyk AC, Alfinito PD et al (2009) Simultaneous telemetric monitoring of tail-skin and core body temperature in a rat model of 
thermoregulatory dysfunction. J Neurosci Methods 178:270-275. https:// doi.org/10.1016/j.jneumeth.2008.12.013

13. Uchida Y, Nagashima K, Yuri K (2017) Systemic estradiol administration to ovariectomized rats facilitates thermoregulatory behavior in a cold environment. Brain Res 1670:125-134. https://doi.org/10.1016/j.brain res.2017.06.009

14. Yuasa $H$, Ono Y, Fukabori Y et al (1998) Usefulness of the estrogen releasing silastic tubing - estrogenic effect of seminal vesicle in immature castrated rats. Kitakanto Med J 48:15-18. https://doi.org/10.2974/kmj.48.15

15. Smith MS, Freeman ME, Neill JD (1975) The control of progesterone secretion during the estrous cycle and early pseudopregnancy in the rat: prolactin, gonadotropin and steroid levels associated with rescue of the corpus luteum of pseudopregnancy. Endocrinology 96:219-226

16. Kleiber M (1947) Body size and metabolic rate. Physiol Rev 27:511-541. https://doi.org/10.1152/physrev.1947.27.4.511

17. Faul F, Erdfelder E, Lang A-G, Buchner A (2007) G*Power 3: a flexible statistical power analysis program for the social, behavioral, and biomedical sciences. Behav Res Methods 39:175-191. https://doi.org/10.3758/BF031 93146

18. Bradley SR, Deavers DR (1980) A re-examination of the relationship between thermal conductance and body weight in mammals. Comp Biochem Physiol Part A Physiol 65:465-476. https://doi.org/10.1016/03009629(80)90060-2

19. Kleiber M (1972) A new Newton's law of cooling? Science 178:1283-1285

20. Mittelman-Smith MA, Williams H, Krajewski-Hall SJ et al (2012) Role for kisspeptin/neurokinin B/dynorphin (KNDy) neurons in cutaneous vasodilatation and the estrogen modulation of body temperature. Proc Natl Acad Sci USA 109:19846-19851. https://doi.org/10.1073/pnas.12115 17109

21. Liu L, Zhou L, Yang X et al (2018) 17ß-estradiol attenuates ovariectomyinduced bone deterioration through the suppression of the ephA2 ephrinA2 signaling pathway. Mol Med Rep 17:1609-1616. https://doi. org/10.3892/mmr.2017.8042

22. El-Mas MM, Abdel-Rahman AA (2009) Longitudinal assessment of the effects of oestrogen on blood pressure and cardiovascular autonomic activity in female rats. Clin Exp Pharmacol Physiol 36:1002-1009. https:// doi.org/10.1111/j.1440-1681.2009.05192.x

23. Nishimura Y, Mabuchi K, Omura N et al (2020) Fluoxetine mimics the anorectic action of estrogen and its regulation of circadian feeding in ovariectomized female rats. Nutrients. https://doi.org/10.3390/nu120 30849

24. Nishimura Y, Mabuchi K, Takano A et al (2017) S-equol exerts estradiollike anorectic action with minimal stimulation of estrogen receptor-a in ovariectomized rats. Front Endocrinol. https://doi.org/10.3389/fendo .2017 .00281

25. Takamata A, Torii K, Miyake K, Morimoto K (2011) Chronic oestrogen replacement in ovariectomised rats attenuates food intake and augments c-Fos expression in the suprachiasmatic nucleus specifically during the light phase. Br J Nutr 106:1283-1289. https://doi.org/10.1017/ S0007114511001607

26. Uchida Y, Kano M, Yasuhara S et al (2010) Estrogen modulates central and peripheral responses to cold in female rats. J Physiol Sci 60:151-160. https ://doi.org/10.1007/s12576-009-0079-x

27. Stachenfeld NS, Silva C, Keefe DL (2000) Estrogen modifies the temperature effects of progesterone. J Appl Physiol 88:1643-1649. https://doi. org/10.1152/jappl.2000.88.5.1643
28. Bowe J, Li XF, Kinsey-Jones J et al (2006) The hop phytoestrogen, 8-prenylnaringenin, reverses the ovariectomy-induced rise in skin temperature in an animal model of menopausal hot flushes. J Endocrinol 191:399-405. https://doi.org/10.1677/joe.1.06919

29. Berendsen $\mathrm{HH}$, Weekers AH, Kloosterboer HJ (2001) Effect of tibolone and raloxifene on the tail temperature of oestrogen-deficient rats. Eur J Pharmacol 419:47-54

30. Szawka RE, Rodovalho GV, Monteiro PM et al (2009) Ovarian-steroid modulation of locus coeruleus activity in female rats: involvement in luteinising hormone regulation. J Neuroendocrinol 21:629-639. https:// doi.org/10.1111/j.1365-2826.2009.01880.x

31. Nagashima K, Nakai S, Matsue K et al (2003) Effects of fasting on thermoregulatory processes and the daily oscillations in rats. Am J Physiol Regul Integr Comp Physiol 284:R1486-R1493. https://doi.org/10.1152/ ajpregu.00515.2002

32. Uchida Y, Tokizawa K, Nakamura M et al (2012) Tail position affects the body temperature of rats during cold exposure in a low-energy state. J Comp Physiol A Neuroethol Sens Neural Behav Physiol 198:89-95. https ://doi.org/10.1007/s00359-011-0690-1

33. Young AA, Dawson NJ (1982) Evidence for on-off control of heat dissipation from the tail of the rat. Can J Physiol Pharmacol 60:392-398

34. Kanosue K, Nakayama T, Tanaka H et al (1990) Modes of action of local hypothalamic and skin thermal stimulation on salivary secretion in rats. J Physiol 424:459. https://doi.org/10.1113/JPHYSIOL.1990.SP018077

35. Yanase M, Kanosue K, Yasuda H, Tanaka H (1991) Salivary secretion and grooming behaviour during heat exposure in freely moving rats. J Physiol 432:585-592. https://doi.org/10.1113/jphysiol.1991.sp018402

36. Tanaka H, Kanosue K, Nakayama T, Shen Z (1986) Grooming, body extension, and vasomotor responses induced by hypothalamic warming at different ambient temperatures in rats. Physiol Behav 38:145-151. https:// doi.org/10.1016/0031-9384(86)90145-9

37. Nolan C, Proietto J (1995) The effects of oophorectomy and female sex steroids on glucose kinetics in the rat. Diabetes Res Clin Pract 30:181-188 https://doi.org/10.1016/0168-8227(95)01193-5

38. Brown LM, Clegg DJ (2010) Central effects of estradiol in the regulation of food intake, body weight, and adiposity. J Steroid Biochem Mol Biol 122:65-73. https://doi.org/10.1016/j.jsbmb.2009.12.005

39. Xu Y, Nedungadi TP, Zhu L et al (2011) Distinct hypothalamic neurons mediate estrogenic effects on energy homeostasis and reproduction. Cell Metab 14:453-465. https://doi.org/10.1016/..cmet.2011.08.009

40. Marques DA, de Carvalho D, da Silva GSF et al (2017) Influence of estrous cycle hormonal fluctuations and gonadal hormones on the ventilatory response to hypoxia in female rats. Pflugers Arch Eur J Physiol 469:12771286. https://doi.org/10.1007/s00424-017-2022-y

41. Marques DA, de Carvalho D, da Silva GSF et al (2015) Ventilatory, metabolic, and thermal responses to hypercapnia in female rats: effects of estrous cycle, ovariectomy, and hormonal replacement. J Appl Physiol 119:61-68. https://doi.org/10.1152/japplphysiol.00254.2015

\section{Publisher's Note}

Springer Nature remains neutral with regard to jurisdictional claims in published maps and institutional affiliations.

Ready to submit your research? Choose BMC and benefit from:

- fast, convenient online submission

- thorough peer review by experienced researchers in your field

- rapid publication on acceptance

- support for research data, including large and complex data types

- gold Open Access which fosters wider collaboration and increased citations

- maximum visibility for your research: over 100M website views per year

At BMC, research is always in progress.

Learn more biomedcentral.com/submissions 